\title{
CRITÉRIOS CLİNICOS E INSUMOS UTILIZADOS NO BANHO DE RECÉM-NASCIDOS PRÉ-TERMO DE MUITO BAIXO PESO
}

Samara Cecilia Sabino Pereira da Silva ${ }^{1}$ Elizandra Cassia da Silva Oliveira ${ }^{1}$ Regina Célia de Oliveira ${ }^{2}$ Ana Virginia Rodrigues Verissimo² Katia Maria Mendes ${ }^{3}$ https://orcid.org/0000-0001-8075-5144 https://orcid.org/0000-0002-4785-4375 https://orcid.org/0000-0002-6559-5872 https://orcid.org/0000-0002-4278-5315 https://orcid.org/0000-0001-6395

Objetivo: Identificar os critérios clínicos e insumos utilizados para a administração do primeiro banho em recém-nascidos prematuros de muito baixo peso, internados em unidades de terapia intensiva neonatal. Métodos: Estudo descritivo, com abordagem quantitativa, com base no Método Canguru/Ministério da Saúde, realizado em cinco unidades de terapia intensiva neonatal; população composta por 82 profissionais da equipe de enfermagem. Resultados: Os critérios clínicos não apontados na avaliação foram 19,5\% para a saturação de oxigênio, 23,2\% frequência cardiaca e 29,3\% frequência respiratória. Os insumos utilizados na realização do primeiro banho: água de torneira aquecida (56,1\%), com controle bacteriológico (52,4\%), sabão líquido (89,0\%), com pH neutro (76,8\%). Conclusão: A não observância dos sinais clínicos e os insumos inadequados para a realização do banho do recém-nascido prematuro de muito baixo peso podem colocar em risco a segurança do paciente, emergindo adequações para fortalecimento da prática clínica da enfermagem.

Descritores: Recém-Nascido de Muito Baixo Peso; Unidades de Terapia Intensiva Neonatal; Enfermagem Neonatal; Banhos.

\section{CLINICAL CRITERIA AND INPUTS USED IN THE BATH OF VERY LOW BIRTH WEIGHT PRETERM NEWBORNS}

Objective: To identify the clinical criteria and inputs used for the administration of the first bath in a very low birth weight premature newborns in neonatal intensive care units. Methods: descriptive study, with a quantitative approach based on the Kangaroo/Ministry of Health Method, carried out in five neonatal intensive care units; population composed of 82 professionals from the nursing team. Results: The clinical criteria not mentioned in the evaluation were $19.5 \%$ for oxygen saturation, $23.2 \%$ heart rate and $29.3 \%$ respiratory rate. The inputs used in the first bath: heated tap water (56.1\%), with bacteriological control (52.4\%), liquid soap (89.0\%), with neutral pH (76.8\%). Conclusion: Failure to observe clinical signs and inadequate supplies for bathing the very low birth weight premature newborn can put patient safety at risk; emerging adaptations to strengthen clinical nursing practice.

Descriptors: Infant, Very Low Weight; Neonatal Intensive Care Units; Neonatal Nursing; Baths.

\section{CRITERIOS CLÍNICOS E INSUMOS UTILIZADOS EN EL BAÑO DE RECIÉN NACIDOS PREMATUROS DE MUY BAJO PESO AL NACER}

Objetivo: Identificar los criterios clínicos y los insumos utilizados para la administración del primer baño en recién nacidos prematuros de muy bajo peso al nacer en unidades de cuidados intensivos neonatales. Método: Estudio descriptivo, con enfoque cuantitativo, basado en el Método Canguro/Ministerio de Salud, realizado en cinco unidades de cuidados intensivos neonatales; población compuesta por 82 profesionales del equipo de enfermería. Resultados: Los criterios clínicos no mencionados en la evaluación fueron $19.5 \%$ para la saturación de oxígeno, $23.2 \%$ de frecuencia cardiaca y $29.3 \%$ de frecuencia respiratoria. Los insumos utilizados en el primer baño: agua caliente del grifo (56.1\%), con control bacteriológico (52.4\%), jabón líquido (89.0\%), con pH neutro (76.8\%). Conclusión: El incumplimiento de los signos clínicos y los suministros inadecuados para bañar al recién nacido prematuro de muy bajo peso pueden poner en riesgo la seguridad del paciente; adaptaciones emergentes para fortalecer la práctica clínica de enfermería.

Descriptores: Infantil, Muy Bajo Peso; Unidades de Cuidados Intensivos Neonatales; Enfermería Neonatal; Baños.

${ }^{1}$ Hospital das Clínicas da Universidade Federal de Pernambuco, PE.

${ }^{2}$ Faculdade de Enfermagem da Universidade de Pernambuco, PE.

${ }^{3}$ Centro Integrado de Saúde Amaury de Medeiros, Universidade de Pernambuco, PE.

Autor Correspondente: Elizandra Cassia da Silva Oliveira - Email:elizandra.cassia@bol.com.br

Recebido: 21/1/2020 Aceito: 09/4/2020 


\section{INTRODUÇÃO}

A Organização Mundial de Saúde define recém-nascido prematuro como toda criança nascida viva antes de 37 semanas de gestação. Quanto ao peso de nascimento, o recém-nascido (RN) poderá ser considerado de muito baixo peso ao nascer quando o peso de nascimento for inferior a 1.500 gramas, independentemente da idade gestacional.(1) Apesar de representarem uma pequena parcela de 1 a $2 \%$ entre os recém-nascidos vivos, são ao mesmo tempo responsáveis por aproximadamente 25 a 30\% da mortalidade infantil e 50 a $70 \%$ da mortalidade neonatal. ${ }^{(2)}$

Em virtude do avanço tecnológico e da introdução de novas práticas assistenciais no cuidado ao recém-nascido prematuro de muito baixo peso, percebe-se um aumento da sobrevida neste grupo, na medida em que é assegurada a oportunidade de receber assistência especializada na Unidade de Terapia Intensiva Neonatal (UTIN). ${ }^{(3)}$

Observa-se que, na assistência direta e indireta ao recém-nascido na UTIN, o enfermeiro destaca-se na prestação do cuidado integral, que abrange desde a parte educativa aos pais até a coordenação, supervisão e execução dos cuidados de enfermagem junto à equipe de saúde. Dentre os procedimentos assistenciais realizados pela equipe de enfermagem na UTIN, destacam-se a punção venosa periférica, instalação e manutenção de cateteres orogástricos e vesicais, instalação da nutrição parenteral, realização de curativos, aspiração de vias aéreas, manutenção da intubação traqueal e administração do banho. ${ }^{(4)}$

Para o Ministério da Saúde (MS), o banho ao recém-nascido prematuro de muito baixo peso resulta em um nível alto de manipulação, que pode produzir diversas reações ao recém-nascido, entre elas, a hipotermia e os distúrbios cardiorrespiratórios. ${ }^{1}$ Assim, o banho destes clientes exige uma avaliação conjunta dos sinais clínicos e insumos utilizados, que promovam segurança ao recém-nascido e ao profissional que o executa. Desta forma, a estabilidade hemodinâmica é um critério clínico essencial para a indicação do banho em recém-nascidos prematuros de muito baixos pesos internados em UTIN. Quando essa avaliação não é bem definida, poderá levar a piora clínica, aumento do tempo de internamento e custos para o estabelecimento de saúde. Entre os critérios clínicos para avaliar a estabilidade hemodinâmica destacam-se as frequências cardíaca e respiratória, cor da pele, tônus muscular, temperatura, entre outros. ${ }^{(5)}$

Outras características são encontradas no recém-nascido prematuro de muito baixo peso, tais como as peculiaridades da pele. $\mathrm{O}$ pH elevado da pele está associado com a formação tardia do manto ácido, que desempenha uma barreira bacteriostática. Sua não consolidação possibilita o desenca- deamento de infecções, na medida que aumenta sua permeabilidade e absorção de soluções aplicadas. ${ }^{\left({ }^{6}\right)}$ Estudo revela que $25 \%$ dos recém-nascidos prematuros de muito baixo peso terão ao menos um episódio de sepse até o terceiro dia de vida, em situações em que a pele é a principal porta de entrada.(7) Já no mundo, 350.000 recém-nascidos prematuros de muito baixo peso morrem decorrente de sepse e meningite, e 50\% desses óbitos são na primeira semana de vida, quando a função de barreira da epiderme encontra-se mais comprometida. Nos paises em desenvolvimento os índices de mortalidade chegar até $70 \% .^{(8-9)}$

No entanto, o banho tem sido considerado um procedimento de rotina em algumas UTIN em que a execução sem critérios pré-estabelecidos poderá implicar em piora clínica ao recém-nascido prematuro de muito baixo peso. Atrelado a isso, as evidências científicas são incipientes para subsidiar a realização do procedimento. Assim, esse estudo objetivou identificar os critérios clínicos e insumos utilizados para a administração do primeiro banho em recém-nascido prematuro de muito baixo peso internado em UTIN.

\section{MÉTODO}

\section{Tipo de estudo}

Estudo descritivo, exploratório, transversal, com análise quantitativa dos dados.

\section{População do estudo}

A população do estudo foi composta por toda a equipe de enfermagem plantonista diurna das cinco UTIN participantes, cuja amostra foi de conveniência e correspondeu a $80 \%$ da população estudada.

A escolha pelos plantonistas diurnos se deu pelo fato de a administração do banho no recém-nascido ser realizada neste turno, conforme as rotinas institucionais dos hospitais pesquisados. Como critério de inclusão foi considerado o funcionário com no mínimo um ano de experiência assistencial direta ao recém-nascido na unidade de terapia intensiva neonatal.

\section{Local do estudo}

O estudo foi realizado em cinco UTIN de instituições públicas de saúde de referência, localizadas na Zona da Mata e Região Metropolitana, no estado de Pernambuco. As da Região Metropolitana foram o Hospital das clínicas da UFPE com 08 leitos e a equipe de enfermagem composta por 17 enfermeiras e 28 técnicos de enfermagem, o Hospital Agamenon Magalhães com 16 leitos e a equipe de enfermagem composta por 12 enfermeiras e 48 técnicos de enfermagem, o Hospital Barão de Lucena com 18 leitos e a equipe de enfermagem 
composta por 13 enfermeiras e 48 técnicos de enfermagem e o Centro Integrado de Saúde Amaury de Medeiros (CISAM-UPE) com 10 leitos e a equipe de enfermagem composta por 06 enfermeiras e 30 técnicos de enfermagem. A UTIN da zona da mata foi o Hospital João Murilo de Oliveira com 10 leitos e a equipe de enfermagem composta por 14 enfermeiras e 32 técnicos de enfermagem. A pesquisa foi realizada no período de julho de 2017 a janeiro de 2018

\section{Coleta de dados}

Os dados foram coletados pelo próprio pesquisador, utilizando um questionário semiestruturado baseado no manual técnico "Atenção humanizada ao recém-nascido: Método Canguru", do Ministério da saúde.(1) Para a coleta, o funcionário era convidado para um local reservado, dentro do próprio setor, para preenchimento e devolução do questionário caso concordasse em participar da pesquisa.

A primeira parte do questionário constou dos critérios clínicos do recém-nascido prematuro de muito baixo peso para a administração do primeiro banho: sinais clínicos avaliados e o tempo de vida pós-natal. A segunda parte constou da utilização dos insumos no primeiro banho: tipo de água, controle bacteriológico da água, tipo e pH do sabão. Para garantir a aplicabilidade do instrumento, foi realizado um teste piloto para adaptação das perguntas com o intuito de garantir um bom entendimento dos participantes.

\section{Procedimentos de análise dos dados}

Os dados obtidos foram organizados e analisados de forma descritiva, utilizando o EPI INFO, versão 3.5.2. Para verificar a associação entre duas variáveis categóricas foi utilizado o teste Qui-quadrado de Pearson e/ou teste da Razão de Verossimilhança. A margem de erro utilizada nas decisões dos testes estatísticos foi de $5 \%$.

\section{Procedimentos éticos}

O projeto foi aprovado pelo Comitê de Ética em Pesquisa conforme parecer $n=1.595 .406$, atendendo as exigências éticas propostas pela Resolução n. 466/12, do Conselho Nacional de Saúde. Após a assinatura do TCLE pelos participantes da pesquisa.

\section{RESULTADOS}

Participaram da pesquisa 82 profissionais de enfermagem dos cincos hospitais públicos estudados, dos quais $74,4 \%$ eram técnicos de enfermagem e $25,6 \%$ enfermeiros.

$\mathrm{Na}$ avaliação dos critérios clínicos elencados para a execução do primeiro banho em recém-nascidos de muito baixo peso pela equipe de enfermagem, 93,9\% da equipe de enfer- magem reconheceu a importância da avaliação dos critérios clínicos. Entretanto, 19,5\% não apontaram avaliar a saturação de oxigênio, 23,2\% a frequência cardíaca e 29,3\% a frequência respiratória. Todavia, não houve significância estatística entre as variáveis analisadas entre as categorias profissionais (enfermeiros e técnicos de enfermagem) (Tabela 1).

Tabela 1 - Critérios clínicos utilizados pela equipe de enfermagem no primeiro banho de recém-nascidos prematuros de muito baixo peso ao nascer em unidade de terapia intensiva neonatal ( $n=82)$. Recife, PE, Brasil, 2018.

\begin{tabular}{|ccccc}
\hline \multirow{2}{*}{ Variável } & Enfermeiro & $\begin{array}{c}\text { Técnico de } \\
\text { Enfermagem }\end{array}$ & Grupo total & Valor $\mathbf{p}$ \\
\cline { 2 - 5 } & $\mathbf{n}(\%)$ & $\mathbf{n}(\%)$ & $\mathbf{n}(\%)$ & \\
\multicolumn{2}{l}{ Sinais clinicos são avaliados antes da execução do banho } \\
Sim & $21(100)$ & $56(91,8)$ & $77(93,9)$ & $p^{(1)}=0,321$ \\
Não & - & $5(8,2)$ & $5(6,1)$ &
\end{tabular}

Temperatura Corporal

$\begin{array}{lcccc}\text { Sim } & 19(90,5) & 56(91,8) & 75(91,5) & p^{(1)}=1,000 \\ \text { Não } & 2(9,5) & 5(8,2) & 7(8,5) & \end{array}$

Saturação de oxigênio
$\begin{array}{ccccc}\text { Sim } & 18(85,7) & 48(78,7) & 66(80,5) & \\ \text { Não } & 3(14,3) & 13(21,3) & 16(19,5) & p^{(1)}=0,750\end{array}$

Frequência cardiaca

$\begin{array}{lllll}\text { Sim } & 16(76,2) & 47(77,0) & 63(76,8) & \\ \text { Não } & 5(23,8) & 14(23,0) & 19(23,2) & p^{(1)}=1,000\end{array}$

Frequência respiratória
$\begin{array}{lllll}\text { Sim } & 16(76,2) & 42(68,9) & 58(70,7) & \\ \text { Não } & 5(23,8) & 19(31,1) & 24(29,3) & p^{(2)}=0,524\end{array}$

Tempo de vida pós-natal (dias)

$\begin{array}{lllll}\text { Até um dia } & 6(28,6) & 21(34,4) & 27(32,9) & \\ \text { 2 a 14 } & 5(23,8) & 17(27,9) & 22(26,8) & \\ 15 \text { a 30 } & 6(28,6) & 10(16,4) & 16(19,5) & \\ \begin{array}{l}\text { Não tem } \\ \text { padronização }\end{array} & 4(19,0) & 13(21,3) & 17(20,7) & \end{array}$

(1)Teste Exato de Fisher. (2)Teste Qui-quadrado de Pearson

Em relação aos insumos utilizados na realização do primeiro banho aos recém-nascidos prematuros de muito baixo peso ao nascer, observa-se na Tabela 2 que o tipo de água mais citado foi o de torneira aquecida (56,1\%), seguida de água destilada aquecida (26,8\%). No controle bacteriológico da água, 52,4\% da equipe de enfermagem apontou que havia controle bacteriológico na unidade. Entretanto, 42,7\% não sabiam informar e 4,9\% responderam não saber.

Quanto ao tipo de sabão utilizado, $89,0 \%$ da equipe de en- 
fermagem citou ser o sabão líquido e 76,8\%, com pH neutro. Não foi observado significância estatística entre as variáveis analisadas e as categorias profissionais (enfermeiros e técnicos de enfermagem).

Tabela 2 - Insumos utilizados pela equipe de enfermagem no primeiro banho de recém-nascidos prematuros de muito baixo peso ao nascer em unidade de terapia intensiva neonatal $(n=82)$. Recife, PE, Brasil, 2018.

\begin{tabular}{|c|c|c|c|c|}
\hline \multirow{2}{*}{ Variável } & Enfermeiro & $\begin{array}{c}\text { Técnico de } \\
\text { Enfermagem }\end{array}$ & $\begin{array}{l}\text { Grupo } \\
\text { total }\end{array}$ & \multirow[t]{2}{*}{ Valor $\mathrm{p}$} \\
\hline & n (\%) & n (\%) & n (\%) & \\
\hline \multicolumn{5}{|c|}{ Tipo de água utilizada } \\
\hline $\begin{array}{l}\text { Água de } \\
\text { torneira } \\
\text { aquecida }\end{array}$ & $12(57,1)$ & $34(55,7)$ & $46(56,1)$ & \multirow{5}{*}{$\begin{array}{l}p^{(1)}= \\
0,649\end{array}$} \\
\hline $\begin{array}{l}\text { Água filtrada } \\
\text { ou fervida }\end{array}$ & - & $5(6,1)$ & $5(6,1)$ & \\
\hline & & & & \\
\hline $\begin{array}{l}\text { Água } \\
\text { destilada } \\
\text { aquecida }\end{array}$ & $6(28,6)$ & $16(26,2)$ & $22(26,8)$ & \\
\hline $\begin{array}{l}\text { Água } \\
\text { deionizada } \\
\text { aquecida }\end{array}$ & $3(14,3)$ & $6(9,8)$ & $9(11,0)$ & \\
\hline
\end{tabular}

Controle bacteriológico da água utilizada

$\begin{array}{lcccc}\text { Sim } & 13(61,9) & 30(49,2) & 43(52,4) & \\ \text { Não } & 1(4,8) & 3(4,9) & 4(4,9) & \mathrm{p}^{(1)}= \\ \text { Não sabe } & 7(33,3) & 28(45,9) & 35(42,7) & \end{array}$

Tipo de sabão utilizado

$\begin{array}{lcccc}\begin{array}{l}\text { Sabão } \\ \text { liquido }\end{array} & 19(90,5) & 54(88,5) & 73(89,0) & \begin{array}{c}\mathrm{p}^{(1)}= \\ 1,000\end{array} \\ \begin{array}{l}\text { Clorexidina } \\ \text { degermante }\end{array} & 2(9,5) & 5(8,2) & 7(8,5) & \\ \begin{array}{l}\text { Não usa } \\ \text { sabão }\end{array} & - & 2(3,3) & 2(2,4) & \end{array}$

Se sabão, qual é o pH do sabão utilizado

$\begin{array}{lcccc}\text { pH neutro } & 20(95,2) & 43(70,5) & 63(76,8) & p^{(1)}= \\ \text { Não sabe } & 1(4,8) & 16(26,2) & 17(20,7) & 0,061\end{array}$

${ }^{1)}$ Através do teste Exato de Fisher.

\section{DISCUSSÃO}

O banho realizado nos recém-nascidos prematuros de muito baixo peso em UTIN deve ser de forma protetiva, a fim de promover conforto, segurança e, especialmente, reduzir as complicações clínicas associadas ao procedimento. A hipo- termia promovida durante a realização do banho é uma das complicações mais evidenciadas e investigadas nesta população, em virtude da sua produção limitada de calor, baixa reserva de gordura marrom e glicogênio.(4,10,11) A hipotermia é responsável por repercussões hemodinâmicas graves, revelada neste estudo como o critério clínico mais avaliado pela equipe de enfermagem, para o primeiro banho.

Estudos realizados no México e na Coreia do Sul também identificaram que, durante o banho nos recém-nascidos prematuros de muito baixo peso, há significativa queda da saturação de oxigênio, aumento da frequência cardíaca e persistência da cianose de pele, além da necessidade de altas temperaturas da incubadora, para restabelecimento da temperatura corporal entre $36,5^{\circ} \mathrm{C}$ e $37,5^{\circ} \mathrm{C}$, e aumento da oferta de oxigênio para manter a saturação entre $86 \%$ e $96.5 \%$. Portanto, caso haja a persistência da taquicardia, um baixo débito cardiaco pode ocorrer, reduzindo a perfusão sistêmica e ocasionando hipotensão e acidose metabólica. ${ }^{(12-13)}$

Quanto ao sistema respiratório, o recém-nascido prematuro de muito baixo peso, apresenta ainda menos fibras tipo I, que são resistentes à fadiga e o tórax mais instável, que podem aumentar a frequência respiratória e causar fadiga, apneia, aumento dos padrões ventilatórios e maiores riscos a barotraumas durante momentos de stress, em que o banho está inserido. ${ }^{(14)}$

A monitorização clínica destes parâmetros (frequência cardiaca e respiratória) deve ser uma prática consolidada na assistência de enfermagem durante a rotina dos banhos realizados, entretanto, não foi evidenciada como rotina dos profissionais, nos resultados desta pesquisa, o que pode comprometer a qualidade da assistência de enfermagem relacionada a execução do banho.

Para segurança do recém-nascido prematuro de muito baixo peso que recebe o banho, o tempo de duração deve ser breve, com duração entre 5 e 7 minutos, para evitar o estresse após a primeira semana de vida. Além disso, estudo recomenda a limpeza da pele ao nascer apenas nos casos de infecção ao vírus da imunodeficiência humana, hepatite $B$ e história materna incerta devido a doenças de transmissão transplacentária, como forma de reduzir a colonização da pele, pela presença de sangue e vernix caseoso. ${ }^{(14,15)}$

Já o MS recomenda que os banhos de todos os recém-nascidos em UTIN sejam realizados apenas quando necessário, na presença de sujidade visível, limitando-se ao máximo de duas vezes por semana. ${ }^{(1)} \mathrm{Na}$ prática assistencial das equipes avaliadas neste estudo observou-se que a realização do banho ocorre de forma não individualizada e mecanizada, com predomínio nas primeiras 24 horas de vida ou sem padronização, contrapondo a recomendação do MS.

Assim, a hora de ouro ao nascer, considerada essencial para a sobrevida e o prognóstico do recém-nascido prematu- 
ro de muito baixo peso, e sua adaptação ao meio extrauterino, pode não estar sendo valorizada pela equipe de enfermagem, possivelmente por não conhecerem as complicações associadas à realização precoce do primeiro banho. Desta forma, reforça-se a importância da educação permanente na capacitação destes profissionais, dentro do ambiente intra-hospitalar.

O uso de água da torneira para o banho dos RN, sem conhecimento sobre a existência de controle bacteriológico da água pelos profissionais estudados contraria a recomendação dos protocolos americanos, que recomendam o uso de água potável morna, associada a um produto de limpeza suave, que apresente $\mathrm{pH}$ fisiologicamente adequado (5,5 a 7), para o primeiro banho dos RN de muito baixo peso. ${ }^{(6)}$

Em relação aos produtos utilizados para o banho, a grande maioria dos profissionais estudados utilizava sabonete líquido, contrapondo recomendação da Association of Women's Health Obstetric and Neonatal Nurses, que proconiza utilizar somente água morna com chumaço de algodão. A utilização de agentes tópicos pode destruir o manto ácido da pele do RN, desencadeando o aumento no seu pH, a mudança na composição da flora bacteriana cutânea e na atividade das enzimas da epiderme. ${ }^{(16)}$ Além disso, há interferências também na dissolução da gordura da superfície da epiderme, que predispõe à secura e à descamação da pele do recém-nascido. ${ }^{(17-18)}$

Entretanto, pesquisas consideram a hipótese de que o banho dado apenas com água é ineficaz e pode alcalinizar a pele, pois aumenta o $\mathrm{pH}$ de 5,5 para 7,5 devido à capacidade de tamponamento da água. Em consequência disto, o manto ácido não consegue desenvolver sua função bacteriostática, permitindo ação de agentes patógenos, o que reforça a necessidade de inserir um sabão que apresente pH ácido. (11.19)

Quanto ao pH do sabão utilizado, apesar de a maioria dos profissionais estudados utilizarem sabão neutro, a literatura científica indica o $\mathrm{pH}$ deve ser levemente ácido. Considerando a maturidade da pele do RN, o uso de produtos com o pH baixo $(5,5)$ pode ajudar a desenvolver mais rapidamente o estrato córneo e o manto ácido do RN, pois, como citado, ela é essencial para a proteção contra agentes penetrantes exógenos, agentes infecciosos e para a manutenção da função imunológica inata. ${ }^{(2)}$

Todavia, o uso de sabão com pH elevado (alcalino) provoca um aumento do potencial de Hidrogênio da pele, o que, por sua vez, promove também a desidratação, a irritabilidade e a alteração da flora bacteriana. Pesquisas apontam que a aplicação de tratamentos ácidos tem sido proposta para tratar a inflamação e normalizar a estrutura e a função do estrato córneo, sendo efetiva também para acelerar a maturação da pele do RN prematuro, a partir da acidificação, bem como para auxiliar no desenvolvimento e manutenção da barreira transcutânea. ${ }^{(11,18)}$

O desconhecimento de parte da equipe de enfermagem sobre o pH do sabão utilizado ressalta a necessidade de as empresas incluírem a informação sobre $\mathrm{pH}$ dos produtos nos rótulos, bem como reforçar que este item seja verificado pelo profissional. Pesquisas realizadas no Brasil e nos Estados Unidos da América destacaram que as marcas mais populares possuem pH entre 11,4l a 6,07. Também foi evidenciado que as marcas mais vendidas não identificam o pH do produto, apenas informam que o produto é neutro, podendo seu $\mathrm{pH}$ ser alcalino. ${ }^{(2,20)}$ Ambas as pesquisas apontam ainda que a inclusão da informação sobre o pH no rótulo do produto permitiria aos pais e aos hospitais comprar mercadorias que condizem com a necessidade do RN e que comprometa a segurança do mesmo.

\section{Limitações do Estudo}

Como limitação, o estudo não permitiu comparar as respostas preenchidas no instrumento da pesquisa ao que efetivamente era realizado na prática da equipe de enfermagem pelos participantes da pesquisa, o que vem a ser recomendado para investigações futuras.

\section{Contribuições do Estudo para a Prática}

Este resultado reflete a necessidade de um novo olhar da equipe de enfermagem na realização do banho ao recém-nascido prematuro de muito baixo peso em UTIN, fundamentado mediante evidências científicas para boas, na tentativa de preservá-los dos prejuízos inerentes desses cuidados na fase neonatal.

\section{CONCLUSÃO}

Esta pesquisa evidenciou que profissionais de enfermagem não observam os sinais clínicos e os insumos adequados para a realização do banho dos RN prematuros de muito baixo peso, o que pode colocar em risco a segurança destes pacientes. Esse conhecimento é essencial para a prática assistencial e, portanto, exige normatizações e rotinas institucionais respaldadas cientificamente para fortalecimento dos processos assistenciais da equipe de enfermagem

Observou-se que há lacunas científicas quanto ao tipo de insumo indicado para o banho dos RN e o tempo ideal para o primeiro banho dos prematuros de muito baixo peso, que podem comprometer a prática de enfermagem.

\section{CONTRIBUIÇÕES DOS AUTORES:}

SCSPS, ECSO: concepção do projeto ou análise e interpretação dos dados; SCSPS, ECSO, RCO: redação do artigo ou revisão crítica relevante do conteúdo intelectual; AVRV, KMM: revisão crítica e revisão final 


\section{REFERÊNCIAS}

1. Ministério da Saúde (BR). Secretaria de Atenção à Saúde, Departamento de Ações Programáticas Estratégicas. Atenção humanizada ao recém-nascido: Método Canguru[internet]. Brasilia: Ministério da Saúde; 2017 [cited 2019 jan.18]. Available from: http://bvsms.saude.gov.br/ bvs/publicacoes/atencao_humanizada_metodo_canguru_manual_3ed.pdf

2. Aredes NDA, Santos RCA, Fonseca LMM. Skin care of premature newborns: integrative review. Rev. Eletr. Enf. [Internet]. 2017 [cited 2019 jan.30]; 19:a59. Available from: http://doi.org/10.5216/ree.v19.43331

3. Mosher S. Comprehensive NICU parental education: beyond baby basics. Neonatal Netw. [internet]. 2017 [cited 2019 jun.20]; $36(1): 18-25$. Available from: https://doi.org/10.1891/0730-0832.36.1.18

4. Ruschel LM, Pedrini DB, Cunha MLC. Hypothermia and the newborn's bath in the first hours of life. Rev. Gaúcha Enferm. [internet]. 2018 [cited 2019 jul. 10]; 39:e20170263. Available from: http://www.scielo.br/scielo.php?script=sci_arttextEpid=S198314472018000100452\&lng=en 5. Loring C, Gregory K, Gargan B, LeBanc V, Lundgren D, Reilly J et al. Tub bathing improves thermoregulation of the late preterm infant. J Obstet Gynecol Neonatal Nurs. [internet]. 2012 [cited 2019 jan.19]; 41(2):171-9. Available from: https://doi.org/10.1111/j.1552-6909.2011.01332.x 6. Lund C. Bathing and Beyond: Current Bathing Controversies for Newborn Infants. Adv Neonatal Care. [internet]. 2016 [cited 2019 jan.19]; 16(Suppl 5S):S13-S20. Available from: https://doi.org/10.1097/ANC.0000000000000336

7. Gao X, Simpson EL. Market trends in baby skin care products and implications for clinical practice. Pediatr Dermatol. [internet] 2014 [cited 2019 jan.19]; 31(6):734-738. Available from: https://doi.org/10.1111/pde.12424

8. Pugliesi VEM, Deutsch AD, Freitas M, Dornaus MFPS, Rebello CM. Efeitos do banho logo após o nascimento sobre as adaptações térmica e cardiorrespiratória do recém-nascido a termo. Rev Paul Pediatr. [Internet]. 2009 [cited 2019 Mar 09]; 27(4):410-415. Available from: http:// www.scielo.br/pdf/rpp/v27n4/v27n4al0

9. Visscher MO, Taylor T, Narendran V. Neonatal intensive care practices and the influence on skin condition. J Eur Acad Dermatology Venereol. [internet]. 2013 [cited 2019 Mar 09]; 27(4):486-93. Available from: https://doi.org/10.1111/j.1468-3083.2012.04470.x

10. Kuller JM. Update on newborn bathing. Newborn Infant. Nurs Rev. [internet]. 2014 [cited 2019 jul.16]; 14(4):166-70. Available from: https:// doi.org/10.1053/j.nainr.2014.10.006

11. Freitas P, Munhoz MMB, Costa P, Kimura AF. Efeito de duas técnicas de banho de imersão na temperatura axilar de recém-nascidos pré-termos: estudo piloto. Texto Contexto Enferm [internet]. 2018 [cited $\quad 2019 \quad$ jul.16]; $\quad 27(1)$ :e0580016. Available from: https://doi.org/10.1590/0104-070720180000580016

12. So HS, You MA, Mun JY,Hwang MJ, Kim HK, Pyeon SJ et al. Effect of trunk-to-head bathing on physiological responses in newborns. J Obstet Gynecol Neonatal Nurs. [internet] 2014 [cited 2019 jul.16]; 43(6):742-751. Available from: https://doi.org/10.1111/1552-6909.12496

13. Bembich S, Fiani G, Strajn T, Sanesi C, Demarini S, Sanson G. Longitudinal Responses to Weighing and Bathing Procedures in Preterm Infants. J Perinat Neonatal Nurs. [internet] 2017 [cited 2019 jul. 10]; 31(1):67-74. Available from: https://doi.org/10.1097/JPN.0000000000000228 14. Tapia-Rombo CA, Mendoza-Cortés U, Uscanga-Carrasco H, Sánchez-García L, Tena-Reyes D, López-Casillas EC. Variations of vital signs and peripheral oxygen saturation in critically ill preterm newborn, after sponge bathing. Rev Invest Clin. [internet]. 2012 [cited 2019 jul. 10]; 64(4):344-53. Available from: https://www.medigraphic.com/pdfs/revinvcli/nn-2012/nnl24e.pdf

15. Medoff Cooper B, Holditch-Davis D, Verklan MT, Fraser-Askin D, Lamp J, Santa-Donato A et al. Newborn clinical outcomes of the AWHONN late preterm infant research-based practice project. J Obstet Gynecol Neonatal Nurs. [internet] 2012 [cited 2019 jul. 10]; 4l(6):774-785. Available from: https://doi.org/10.1111/j.1552-6909.2012.01401.x

16. Lund C. Bathing and Beyond: Current Bathing Controversies for Newborn Infants. Adv Neonatal Care [Internet]. 2016 [cited 2019 mar.06]; 16:S13-20. Available from: https://doi.org/10.1097/ANC.0000000000000336

17. Santos SV, Costa R. Skin care of the newborn: the state of art. J Res Fundam Care Online. [internet] 2015 [cited 2019 jul.16]; 7(3):2887-901. Available from: http://www.seer.unirio.br/index.php/cuidadofundamental/article/view/3814

18. Cunha MLC, Procianoy RS. Banho e colonização da pele do pré-termo. Rev. Gaucha de Enfermagem. 2006 [citado em 2019 jul.18]; 27(2): 203-8. Available from: http://www.lume.ufrgs.br/bitstream/handle/10183/23549/000549530.pdf

19. Mendes BR, Shimabukuro DM, Uber M, Abagge KT. Critical assessment of the pH of children's soap. J Pediatr. [internet] 2016 [cited 2019 jul.14]: 92(3):290-5. Available from: http://www.scielo.br/scielo.php?script=sci_arttextepid=S0021-75572016000300290\&lng=en

20. Colwell A. To Bathe or Not to Bathe: The neonatal question. Neonatal netw. [internet] 2015 [citado em 2019 jul.05]: 34(4):216-9. Available from: https://doi.org/10.1891/0730-0832.34.4.216 